Saudi Journal of Medicine

Abbreviated Key Title: Saudi J Med ISSN 2518-3389 (Print) |ISSN 2518-3397 (Online)

\title{
Does Genetic Makeup of Corona Virus in COVID-19 Disease is as Predicted or is Similar to Other Respiratory Viruses Like Influenza? Still, we Believe in Covid Appropriate Behavior in Spite of Vaccination....... Show Must Go On!
}

\author{
Patil Shital $^{1 *}$, Gajanan Gondhali ${ }^{2}$
}

${ }^{1}$ MD FCCP, Associate Professor, Pulmonary Medicine, MIMSR Medical College, Latur, India

${ }^{2}$ Associate Professor, Internal Medicine, MIMSR Medical College Latur, India

DOI: $10.36348 / \mathrm{sjm} .2022 . v 07 i 01.001$

| Received: 02.12.2021 | Accepted: 05.01.2022 | Published: 10.01.2022

*Corresponding Author: Patil Shital

MD FCCP, Associate Professor, Pulmonary Medicine, MIMSR Medical College, Latur, India

Copyright $\odot 2022$ The Author(s): This is an open-access article distributed under the terms of the Creative Commons Attribution 4.0 International License (CC BY-NC 4.0) which permits unrestricted use, distribution, and reproduction in any medium for non-commercial use provided the original author and source are credited.

\section{INTRODUCTION}

COVID-19 pneumonia is heterogeneous disease with variable effect on lung parenchyma, airways and vasculature leading to long term effects on lung functions. Although Lung is the primary target organ involvement in corona virus disease-19 (COVID19), many patients were shown pulmonary and extrapulmonary manifestations of diseases variably during first and second wave, which occurred as resultant pathophysiological effects of immune activation pathway and direct virus induced lung damage.

\section{Indian perspective [1-12]}

Genetic makeup of corona virus was determining factor for overall outcome in first and second wave, first was classical 'Wuhan variant virus' and second one was mutant 'Delta variant' corona virus; and as mutant in second wave was associated with increased morbidity and mortality. In both the waves, covid pathophysiology were same i.e., immune activation, inflammatory, thrombogenic and direct viral affection to lungs and extrapulmonary tissues. During first wave, predominant age group affected were geriatric population in terms of morbidity and mortality as compared to second wave; in which younger populations were most affected population. If we compare duration of illness till hospitalization and treatment initiation were less than one week in first wave to more than one week in second wave and is the leading cause of mortality in second wave. Health system was unable to cope with emergency hospitalization with increased oxygen requirement with a greater number of patients on ventilatory support in second wave as compared to first wave. Although health system has more prepared for intensive care facility during second wave, due to rapidly growing pandemic and a greater number of cases in second wave, health system was facing shortage of oxygen and ventilator beds across the country.

During first wave, a greater number of cases were having extrapulmonary manifestations or involvement due to covid as compared to pulmonary, and in second wave; predominant pattern was pulmonary versus extrapulmonary. Cardio-vascular involvement were seen more often in first wave as compared to second wave, rational for same was not known, may be 'Wuhan variant virus has more thrombogenic activation syndrome' as compared to Delta variant corona virus. In first wave pseudo-acute coronary syndrome, pulmonary thromboembolism and stroke were documented in more number of cases as compared to second wave. Rapidly evolving pneumonia or 'accelerated acute respiratory distress syndrome' (aARDS) was more commonly documented in second wave and more number of patients were presenting with similar syndrome in second wave with time interval of less than a week, with rapidly deteriorating radiological and clinical-laboratory parameters like increased CT severity score, worsened oxygenation, increased inflammatory markers like CRP, IL-6, Ferritin, LDH, D-dimer, decreased leucocyte and platelet counts. Cytokine storm were documented very commonly with first and second wave, but duration of manifestation of 
Patil Shital \& Gajanan Gondhali.; Saudi J Med, Jan, 2022; 7(1): 1-3

cytokine storm was delayed till second week in first wave as compared to second wave in which cytokine storm presented too early i.e. documented in first 3 days to end of first week of illness may be due to delayed presentation to hospital admission.

During first wave, many patients were presenting with mild symptoms, and response to medical treatment in advanced cases also were excellent with less intensive care requirement including ventilatory support, and overall mortality was less. In second wave many patients were in advanced stage till they access treatment and required intensive care unit treatment including ventilatory support. Overall mortality is 'no significantly different' in first and second wave or slightly more in second wave, as we are dealing with Wuhan variant virus in first wave and mutant Delta variant corona virus in second wave.

Shortage of oxygen and shortage of ventilators was big concern in second wave as compared to first wave in spite of increase in oxygen beds and increase in ventilator beds across the country, this might be faced because of 'exuberant case load' because of rapidly spreading nature of Delta variant corona virus as compared to less mutant first wave Wuhan variant corona virus. Although health system has prepared to tackle more number of covid cases till evolution of second wave, rapid resurgence of cases and rapidly evolving ARDS were determining factor for relatively more mortality in second wave as compared to first wave.

If we compare response to treatment options available to treat covid pneumonia in both the waves, response to steroids and anticoagulation were similar in both the waves, ventilator response was quite satisfactory in first wave as compared to second wave due to milder version of Wuhan variant virus as compared to deadly mutant Delta variant virus. Remdesivir was used in both the waves and documented benefit in terms of decrease in overall duration of hospitalization, while very negligible effect on mortality benefit in both the waves, and whatever mortality benefit was documented; especially in second wave as compared to first wave. Rational for relative more benefit of Remdesivir in second wave was it was used in early stage of illness with steroids as many cases were present in rapidly evolving pneumonia. Similarly, Tocilizumab has used in both the waves whenever 'cytokine storm with hypoxemia' and IL-6 were raised, and it was of minimal to transient use in dealing with it and documented no any benefit in long term analysis. Few reports from country documented some mortality benefit in first wave as compared to second wave, and rational for this was timing of its use in course of evolution of covid disease.

Post covid lung fibrosis and Mucormycosis were two deadlier complications documented during evolution of covid lung pneumonia predominantly in second wave as compared to first wave across the country. Rational for occurrence of both the complications was not clear, post covid fibrosis was documented more commonly in second wave may be related with more virulence of mutant Delta virus in second wave as compared to Wuhan of first wave. Mucormycosis, both pulmonary and extrapulmonary Mucormycosis (eyes, nose, sinuses, cerebral) were documented in second wave, and pathway for same was unclear, may be related to more steroid use in second wave as compared to first wave, corona virus-mucor fungus symbiosis to gain access through mucosal inflammation in airways, humidifier chamber contamination of oxygen supplementation system, but exact reason was unknown.

Regarding covid vaccination, it was not available in first wave, and National covid vaccination policy has been started just eight weeks before starting of second wave. Vaccines used in our country were Covishield and Covaxin and very few people were vaccinated before peak of second wave. Significant difference was documented in terms of severity of illness and response to treatment in vaccinated cases as compared to virgin or unvaccinated population, also significant difference in mortality in vaccinated versus unvaccinated cases.

Point to remember is that, corona virus related COVID-19 is a respiratory virus with propensity of mutations, very short immunity and immune memory i.e. immune escape mechanisms to previous vaccine induced immune memory, capability of minor and major antigenic variations as of influenza virus leading to 'endemic-epidemic' and deadly pandemics, very short immunity after vaccination also, less studied respiratory virus till date.

Vaccination is key step and that too with more updated genetic makeup vaccine which will be prepared by analyzing 'global viral genomic data' is the only option to protect mankind form these smarter virions, and 'covid appropriate behavior' using masks, social distancing to break 'chain of transmission' are key steps for at least coming few years...show must go on!!

\section{REFERENCES}

1. Choudhary, O. P., Priyanka, I. S., \& RodriguezMorales, A. J. (2021). Second wave of COVID-19 in India: Dissection of the causes and lessons learnt. Travel Medicine and Infectious Disease, 43, 102126.

2. Jain, V. K., Iyengar, K. P., \& Vaishya, R. (2021). Differences between First wave and Second wave of COVID-19 in India. Diabetes \& Metabolic Syndrome, 15(3), 1047-1048. doi:10.1016/j.dsx.2021.05.009

3. Madjid, M., Safavi-Naeini, P., Solomon, S. D., \& Vardeny, O. (2020). Potential effects of 
coronaviruses on the cardiovascular system: a review. JAMA cardiology, 5(7), 831-840.

4. Ramos-Casals, M., Brito-Zerón, P., \& Mariette, X. (2021). Systemic and organ-specific immunerelated manifestations of COVID-19. Nature Reviews Rheumatology, 17(6), 315-332.

5. Shang, Y., Pan, C., Yang, X., Zhong, M., Shang, X., Wu, Z., ... \& Chen, D. (2020). Management of critically ill patients with COVID-19 in ICU: statement from front-line intensive care experts in Wuhan, China. Annals of intensive care, 10(1), 124.

6. Alhiyari, M. A., Ata, F., Alghizzawi, M. I., Bilal, A. B. I., Abdulhadi, A. S., \& Yousaf, Z. (2021). Post COVID-19 fibrosis, an emerging complicationof SARS-CoV-2 infection. IDCases, 23, e01041.

7. Rao, V. U., Arakeri, G., Madikeri, G., Shah, A., Oeppen, R. S., \& Brennan, P. A. (2021). COVID19 associated mucormycosis (CAM) in India: a formidable challenge. British Journal of Oral and Maxillofacial Surgery, 59(9), 1095-1098.

8. A nightmare on repeat - India is running out of oxygen again https://www.bbc.com/news/uk56841381

9. Covid-19 second wave: Why are hospitals falling short of ventilators, again? https://www.forbesindia.com/article/take-one-bigstory-of-the-day/covid19-second-wave-why-arehospitals-falling-short-of-ventilators-again/67381/1

10. Tomashek, K. M., \& Dodd, L. E. (2020). Remdesivir for the treatment of covid-19-final report. N Engl J Med, 383, 1813-1826.

11. Salvarani, C., Dolci, G., Massari, M., Merlo, D. F., Cavuto, S., Savoldi, L., ... \& Costantini, M. (2021). Effect of tocilizumab vs standard care on clinical worsening in patients hospitalized with COVID-19 pneumonia: a randomized clinical trial. JAMA internal medicine, 181(1), 24-31.

12. India Fights Corona https://www.mygov.in/covid-19/ 